\title{
Análise institucionalista da integração sul-americana
}

\author{
Institutionalist analysis of South American integration
}

Maria Izabel Mallmann*

\begin{abstract}
Resumo: A integração sul-americana é aqui identificada pelos compromissos regionais assumidos ao longo da década de 1990; lançados durante a $7^{\text {a }}$ Cúpula do Grupo do Rio, de outubro de 1993, seguidos pelas Cúpulas de presidentes da América do Sul (2000, 2002, 2004), pela criação da Iniciativa para a Integração da Infraestrutura Regional Sul-Americana (IIRSA), em 2000, da Comunidade Sul-Americana das Nações (Casa), em 2005 e da União das Nações Sul-Americanas (Unasul), em 2007. Analisa-se o processo tendo como parâmetro as condições e mecanismos apontados por estudos institucionalistas como essenciais para o sucesso de um processo de integração como, por exemplo, a simetria regional e a estabilidade interna, dentre outras. Constata-se que essas duas são as condições mais problemáticas no caso sul-americano, uma vez que interpõem obstáculos ao avanço nas demais. Um balanço do estudo realizado até aqui permite estimar que o processo de integração tende a ser mais longo e errático do que seria desejável, uma vez que se encontra no que poderia ser entendida como fase inicial de implementação de mecanismos e de geração das condições básicas necessárias.
\end{abstract}

Palavras-chave: Integração; América do Sul; Institucionalismo

Abstract: The South-American integration is identified in this work by the regional compromises assumed throughout the 1990's. These regional compromises were launched during the 7th Rio Group Summit Meeting in October 1993. This initial moment was followed by South-American President Summit Meetings (2000, 2002, 2004), by the Initiative for the South-American Infrastructure Integration (IIRSA, 2000), by the South-American Nations Community (Casa, 2005) and by the SouthAmerican Nations Union (Unasul, 2007) creation. This work analyzes this process taking as a parameter the conditions and the mechanisms indicated by institutionalist analyses as a very important means for integration process success such as regional asymmetries and internal stability. We conclude that these two conditions are the most problematic in the South-American case. They pose obstacles to the progress of the

* Doutora em Ciência Política pela Sorbonne - Paris III, professora do PPG em Ciências Sociais e coordenadora do Núcleo de Estudos sobre Relações e Organizações Internacionais na Pucrs, em Porto Alegre, RS, Brasil. <izabel.mallmann@pucrs.br>.

\begin{tabular}{|l|l|l|l|l|l|}
\hline Civitas & Porto Alegre & v. 10 & n. 1 & p. $11-22$ & jan.-abr. 2010 \\
\hline
\end{tabular}


others conditions. This present work preliminary evaluation permits affirming that the integration process will be longer and more roving that it should. This is due to the process being in its initial mechanism implementation, and basic conditions generation phases.

Keywords: Integration; South-America; Institutionalism

\section{Introdução}

Neste trabalho examina-se a integração sul-americana surgida nos anos 1990, à luz da abordagem institucionalista. A integração sul-americana é aqui identificada pelos compromissos regionais assumidos ao longo da década de 1990; lançados durante a $7^{\text {a }}$ Cúpula do Grupo do Rio, de outubro de 1993, seguidos pelas Cúpulas de presidentes da América do Sul (2000, 2002, 2004), pela criação da Iniciativa para a Integração da Infraestrutura Regional SulAmericana (IIRSA), em 2000, da Comunidade Sul-Americana das Nações (Casa) e da União das Nações Sul-Americanas (Unasul), em 2007.

Analisa-se o processo tendo como parâmetro as condições apontadas pelos estudos institucionalistas como essenciais para o sucesso de um processo de integração. Trabalha-se com algumas das condições definidas por Karl Deutsch (1990): compatibilidade de valores, previsibilidade mútua dos comportamentos das unidades e responsabilização mútua (capacidade de trabalhar em estreita colaboração e de responder aos assuntos mais urgentes); e por Joseph Nye $(1971 ; 2002)$ : simetria ou igualdade econômica das unidades, complementaridade positiva das elites, pluralismo (participação de diferentes grupos), capacidade dos estados-membros de se adaptarem e responderem (estabilidade interna). Constata-se que as assimetrias regionais e a instabilidade interna são as condições mais problemáticas no caso sul-americano. Essas condições interpõem obstáculos ao avanço nas demais.

As categorias acima foram recuperadas de literatura especializada sobre a integração européia, o que poderia ser questionável já que se trata de analisar situações em contexto muito diferente. No entanto, entende-se que tais categorias são suficientemente abstratas para assegurar sua aplicabilidade ao caso sul-americano. Além disso, foram evitadas comparações entre os dois processos de integração das quais se pudesse inferir a assimilação indevida de análises e conclusões.

O trabalho está dividido em três partes além desta introdução e das considerações finais. Na primeira parte, são desenvolvidos os conceitos principais e esclarecida a compreensão de integração aqui adotada. $\mathrm{Na}$ 
segunda identifica-se, em linhas gerais, o processo de integração em curso na América do Sul. Na terceira parte, analisam-se as possibilidades de progressão da integração sul-americana à luz do referencial teórico estabelecido. Nas considerações finais realiza-se um balanço da análise dos dados de modo a indicar perspectivas futuras.

\section{Elementos teórico-conceituais}

Nesta parte, são desenvolvidos os principais conceitos e a noção de integração aqui adotada. Como mencionado acima, trabalha-se centralmente com conceitos relativos às condições necessárias para o sucesso dos processos de integração, desenvolvidos por Karl Deutsch e por Joseph Nye.

Embora concordemos com a definição de integração feita por Ernest Haas (1961), segundo a qual a integração conduz, em última instância, à sujeição dos estados a instâncias institucionais mais amplas, às quais diferentes agentes de diversas nacionalidades transferem, mediante incentivos, suas lealdades, entendemos que ela se reporta muito mais a situações já consolidadas de integração do que a processos que, por mais avançados que estejam, não permitem inferir desfechos prováveis.

Consideramos útil lançar mão da distinção entre integração como processo e integração como situação dada, não por entendê-las como excludentes, mas por considerar que, em certos casos, sua avançada institucionalização permite identificar algumas etapas como já vencidas, com ganhos institucionais praticamente irreversíveis para a integração. Diferentemente disso, em outros casos, os níveis de institucionalização não permitem conceber a integração para além do ponto crítico que supostamente evitaria seu retrocesso. Nesses casos, uma gama significativa de iniciativas podem ser entendidas como integracionistas no sentido de que tendem a gerar as condições para tanto. Como situação dada, o processo já teria dado frutos a ponto de permitir a observação de certos aspectos tais como os indicados por Nye (2002): (1) considerável grau de institucionalização ou de politização, ou seja, a existência de instrumentos para resolução dos problemas e conciliação de interesses; (2) efetiva redistribuição dos benefícios, ou seja, compensação das perdas individuais pelos ganhos coletivos do bloco; (3) redistribuição das alternativas que consiste na constante pressão sobre tomadores de decisão em função das vantagens provenientes do avanço do processo; (4) externalização, ou seja, adoção de posições comuns face a terceiros.

Entende-se que, como processo, a integração resulta de iniciativas levadas a termo em diversas frentes, pela adesão dos estados e de outros agentes a variados regimes internacionais. As dinâmicas próprias dessas instâncias 
tendem a criar dependências recíprocas e a condicionar (positivamente ou não) as percepções dos atores. Segundo Nye (2002), o processo de integração afeta a percepção dos agentes em pelo menos três dimensões decisivas para sua continuidade: a percepção a respeito da distribuição dos benefícios, que deverão ser o mais equitativos possível para que a percepção seja positiva; a percepção comum acerca de fatores externos - problemas econômicos, estratégicos, geopolíticos; e a percepção quanto aos custos da integração, que deverão figurar como relativamente baixos para que a percepção seja positiva.

Os obstáculos eventualmente encontrados não impedem a visualização dos progressos do processo como um todo, desde que o mesmo propicie crescentes graus de institucionalização da interdependência. Como a interdependência, em si, não assegura o aumento da cooperação, faz-se necessária a existência de algumas condições para que o processo de integração avance para além de um patamar crítico passível de volta. Grande parte dos estudos sobre integração e cooperação internacional busca entender as condições que permitem aos estados cooperarem em assuntos específicos face aos quais possuem interesses comuns e que são de difícil solução individual nos casos de interdependência complexa. Há grande expectativa de que a partir desses casos pontuais o processo expanda-se a outros domínios, aumentando a interdependência e a demanda por cooperação e institucionalização tornando, assim, o processo irreversível.

Deutsch (apud Braillard, 1990, p. 363-384) identificou pelo menos três condições que se fazem necessárias para o sucesso da integração: compatibilidade de valores; previsibilidade dos comportamentos das unidades, e responsabilização - capacidade de colaborar de forma a responder aos assuntos mais urgentes. ${ }^{1}$ A previsibilidade dos comportamentos reveste-se de importância singular no contexto em análise face à atual instabilidade política sul-americana. Nesses termos, a mútua percepção dos agentes, como visto acima, é fundamental para os desdobramentos da integração e altamente vulnerável à instabilidade política que subtrai capacidade de resposta aos estados.

Isso, por si só, poderia bastar para realizar uma análise da situação sul-americana, porém às, por assim dizer, macrocondições identificadas por Deutsch, agregam-se outras de caráter micro arroladas por Nye (1971, p. 56-58) com o intuito de desenvolver um modelo baseado em "mecanismos processuais e no potencial integrador" (Dougherty e Pfalzgraff, 2003, p. 654) que também são consideradas importantes neste trabalho. São elas: a simetria ou igualdade

\footnotetext{
Ver também Dougherty e Pfaltzgraff (2003, p. 661).
} 
econômica das unidades; a complementaridade positiva das elites; o pluralismo (participação de diferentes grupos) e a capacidade dos estados-membros de se adaptarem e responderem (estabilidade interna). Tais condições decorreriam, segundo o autor, da existência de mecanismos cujas dinâmicas operacionais as gerariam: articulação funcionalista de tarefas ou spillover, acréscimo das transações, articulações deliberadas e formação de coligações, socialização das elites, constituição de blocos regionais, proximidade ideológica e identitária e envolvimento de atores externos ao processo.

\section{"Marcadores" institucionais da integração sul-americana}

Abaixo são identificados, sucintamente, os "marcadores" institucionais da integração em curso na América do Sul, entendendo-se que indicam a trajetória da mesma a partir da manifestação de intenção por parte do Brasil, em 1993, de ampliar o escopo da integração regional na qual encontrava-se engajado. Verificam-se, em linhas gerais, esforços no sentido de alargar a experiência iniciada com o Mercosul, cuja dimensão comercial e econômica entra em letargia na segunda metade da década de 1990. Verifica-se, também, alguma progressão em frentes não propriamente comerciais, como na de infraestrutura, na política e na social.

Como mencionado acima, a integração sul-americana é aqui identificada pelos compromissos assumidos ao longo da década de 1990; lançados durante a $7^{\text {a }}$ Cúpula do Grupo do Rio, de outubro de 1993, seguidos pelas Cúpulas de presidentes da América do Sul (2000, 2002, 2004), pela criação da Iniciativa para a Integração da Infraestrutura Regional Sul-Americana (IIRSA), em 2000, da Comunidade Sul-Americana das Nações (Casa) e da União das Nações Sul-Americanas (Unasul), em 2007. Há quem reporte o início desse processo à assinatura do tratado de Assunção, que criou o Mercado Comum do Sul (Mercosul) em 1991. Contudo, considera-se aqui que o entendimento quanto à pertinência e necessidade de alargar o Mercosul à Comunidade Andina (CAN) é posterior a essa data e corresponde à mudança de entendimento quanto à viabilidade do Mercosul e aos interesses do Brasil em um processo de integração regional.

Ao longo desses anos, o processo sul-americano de integração tem avançado em algumas dimensões, embora em ritmo considerado insuficiente face as suas necessidades de desenvolvimento. Isso se deve em grande medida às situações internas críticas. Em vários quesitos (infraestrutura, instituições, educação, inovação) os países sul-americanos encontram-se bem abaixo da média mundial (Castilla, 2008). Decorrem daí reduzidos estímulos à progressão da integração regional, uma vez que a agenda interna é altamente absorvente. 
Os avanços em termos de integração observados nos anos 1990 não tiveram continuidade na presente década, embora tenham inovado significativamente em relação ao histórico padrão de relacionamento regional que primara, até então, pelo distanciamento e pela competição entre os países sul-americanos. Entre os fatores responsáveis pela estagnação encontra-se a baixa intensidade da interdependência que, por sua vez, decorre das dificuldades estruturais internas acima evocadas. Além disso, a indefinição quanto a uma liderança e a inexistência da produção de bens públicos regionais, tornam o processo bastante incerto (Bouzas; Veiga; Ríos, 2008).

Embora as transações comerciais intrarregionais tenham crescido em termos absolutos desde meados dos anos 1990, observa-se que em termos percentuais houve decréscimo. No biênio 1995-1996, as exportações intrarregionais representavam $25 \%$ do total das exportações sul-americanas em contraste com os $18 \%$ do biênio 2003-2004. Por outro lado, aumentaram os investimentos diretos intrarregionais, notadamente do Chile e do Brasil nos demais países da região (Bouzas; Veiga; Ríos, 2008, p. 333-334).

Segundo Maria Regina Soares de Lima (2009), observa-se o surgimento de um regionalismo diferente, não tanto comercial ou focado na integração física e produtiva, como nos anos 1990, mas "abarcando dimensões sociais, culturais e identitárias". Segundo a autora, "a criação do Fundo para Convergência Estrutural do Mercosul, a constituição do Conselho Sul-Americano de Defesa, a reativação do Convênio de Créditos Recíprocos, o apoio à Unasul e ao Banco do Sul, e a incorporação da Venezuela ao Mercosul" são exemplos dessa nova orientação.

No plano institucional, a experiência sul-americana tem avançado em frentes diversificadas ${ }^{2}$ de forma a assegurar uma agenda mínima comum face aos obstáculos de maior envergadura interpostos à progressão da integração econômica regional (Bouzas; Veiga; Ríos, 2008, p. 335).

De modo geral, a integração sul-americana tem adquirido traços que a diferenciam ligeiramente de uma experiência exclusivamente econômica e comercial, embora os avanços institucionais sejam irrisórios. Outro aspecto digno de reforço é o maior engajamento do Brasil quanto aos custos da integração. Observa-se que o país tem se esquivado cada vez menos a arcar com custos tanto materiais quanto políticos em nome da integração, desenvolvimento e estabilidade regional e, evidentemente, dos interesses

2 São arroladas aqui iniciativas diversas nos planos político diplomático (cúpulas presidenciais, Comunidade Sul-Americana de Nações - Casa, 2005, União de Nações Sul-Americanas Unasul, 2007) e de infraestrutura (Iniciativa para a Integração da Infraestrutura Regional SulAmericana - IIRSA). 
de projeção externa do país. Embora ainda insuficiente, isso representa um avanço em termos do engajamento indispensável ao sucesso do processo de integração.

\section{Condições, mecanismos e percepções}

Considerando o que foi exposto acima, cabe analisar o processo sulamericano de integração a partir da existência ou não das condições e dos mecanismos listados, bem como do ponto de vista da percepção dos atores.

Primeiramente, examinam-se as condições para o sucesso da integração a partir das categorias apontadas acima como imprescindíveis.

Quanto à compatibilidade de valores, observa-se, de certa forma surpreendentemente, que a chegada ao poder de forças políticas situadas à esquerda do espectro político, observada nesta década, não tem se expressado em proximidade de valores quando se trata de traduzi-los em políticas. Em termos declarativos ou retóricos há certa identidade de valores quanto à democracia, à justiça social e à necessidade de desenvolvimento. A concretização desses ideais, contudo, difere significativamente da país a país. Tanto em relação à democracia como regime político mais adequado, quanto à necessidade de emancipação social e de desenvolvimento econômico, observase que o entendimento das vias mais adequadas é muitas vezes conflitante em termos de valores. Enquanto em alguns países as mudanças ocorrem pela gradual transformação das instituições (Brasil, Chile, Uruguai) em outros são despendidos esforços de refundação institucional (Venezuela, Bolívia). Num caso, a estratégia de inclusão política tende a não gerar novos excluídos e, em outro caso, isso não consegue ser evitado. Essas experiências apontam para diferentes cenários políticos que, no limite, seriam excludentes. Essas diferenças são passíveis de serem entendidas face às especificidades históricosociais e políticas de cada país. Contudo, elas não deixam, por isso, de gerar percepções mútuas seja de conservadorismo, seja de extremismo que, no mínimo, colocam em alerta segmentos formuladores e/ou demandantes de políticas públicas, como a externa por exemplo. Além disso, como veremos abaixo, a instabilidade política inerente a tais processos de redistribuição dos benefícios repercute de modo importante na capacidade de resposta externa dos estados.

No que se refere ao pluralismo, ou seja, à vigência de um regime democrático e à possibilidade de incidência de grupos variados na definição de políticas, notadamente da política externa, observa-se que isso tem ocorrido de forma desigual. Enquanto em alguns países se nota a inclusão de novos atores sem maiores prejuízos à ordem precedente (Brasil, Chile, Uruguai) em 
outros tem havido a redução dos mesmos ou a sua ampliação tem ocorrido em detrimento de outros grupos (Venezuela, Bolívia).

De forma semelhante, no que diz respeito à condução do desenvolvimento econômico, desenham-se vias bastante diferenciadas. Embora se observe de forma generalizada a revalorização do estado em todos os casos, há países em que isso ocorre de modo mais extremo. Convivem na região estratégias de desenvolvimento perfeitamente adequadas às regras do capitalismo (Brasil) com outras cuja retórica é anticapitalista (Venezuela). Considera-se que, apesar das similaridades que as retóricas mais estridentes possam encobrir, a concepção de vias de desenvolvimento tão diferenciadas prejudica a projeção de um caminho futuro comum. Como dissemos acima, entende-se que essas diferenças traduzem as peculiaridades nacionais, mas considera-se que nem por isso deixam de ser preocupantes no que diz respeito à viabilização da integração.

Quanto à previsibilidade mútua dos comportamentos das unidades, entende-se que o desempenho de alguns governos tem contribuído para a deterioração desse fator. Não apenas o sistemático questionamento dos contratos por parte de alguns países (Bolívia, Venezuela, Paraguai), mas também a forma como é feito, contribui para fragilizar os laços de confiança e para o isolamento mútuo. A observância aos contratos, o respeito ao direito internacional e a adequação às instituições constrói gradualmente uma teia de relacionamentos pautada na confiança acerca do comportamento dos pares. $\mathrm{O}$ rompimento desses laços é mais célere do que sua tessitura e, quanto à necessidade de preservá-la, não parece haver consenso na região.

No que concerne à complementaridade das elites, observam-se esforços desiguais. Há segmentos das elites políticas regionais cuja performance não contribui para a aproximação em função tanto de ações (Colômbia) como de retórica (Venezuela), em contraste com outros desempenhos (Brasil) que têm buscado sustentar as relações em patamares aceitáveis. Em relação às elites econômicas, a distribuição desigual dos benefícios não facilita complementaridade e fomenta expectativas de ganhos maiores em parcerias com terceiros países.

Em relação à responsabilização mútua, ou seja, à capacidade dos estados de colaborar e de responder conjuntamente aos desafios, a fragilização ou ausência das condições acima tratadas torna essa possibilidade mais remota uma vez que ela depende de grau considerável de confiança e de previsibilidade de parte à parte, e, frequentemente, da existência de valores comuns. Embora em situações-limite essa colaboração ocorra, como no caso do recente conflito entre Equador e Colômbia, isso não é suficiente para depreender-se daí uma 
forte tendência. A situação criada pela mais ostensiva presença militar dos Estados Unidos na Colômbia revela diferenças profundas quanto à própria percepção dos desafios a serem enfrentados por todos.

Quanto à capacidade dos estados-membros para se adaptarem e responderem satisfatoriamente aos desafios, o que depende da estabilidade interna $^{3}$ dos mesmos, observa-se grande vulnerabilidade. De acordo com o Índice de Estabilidade Política (IEP), não houve desde 1994 nenhum semestre sem registro de algum dos indicadores de instabilidade trabalhados. $\mathrm{O}$ golpe de estado e o estado de exceção figuram como alternativas políticas reais. Ameaças de destituição presidencial e revoltas sociais também são amplamente registradas. No período 1994-2004, os países andinos e o Paraguai foram os mais atingidos por crises institucionais (Coutinho, 2008, p. 75-76).

A necessidade de alguma simetria ou igualdade econômica entre as unidades é uma das condições necessárias para o sucesso da integração segundo Nye. E, quanto a isso, observa-se extrema disparidade. Considera-se que as assimetrias, juntamente com a instabilidade política, são os principais condicionantes regionais negativos à integração. No conjunto, a superfície da América do Sul soma mais de 17 milhões de quilômetros quadrados, e nela vivem mais de 380 milhões de pessoas, que geram um produto interno bruto em torno de 1,5 trilhão de dólares. No entanto, as economias são bastante desiguais. Os três maiores países, Argentina, Brasil e Venezuela, ocupam 70\% da superfície total; detêm $78 \%$ do PIB regional e possuem $67 \%$ da população sul-americana. Só o Brasil ocupa mais de $40 \%$ do território, detém $45 \%$ do PIB regional e possui $50 \%$ da população. A quase totalidade dos países sul-americanos é agroexportadora, com baixos índices de industrialização e diversificação econômica. De todos, o Brasil é o único em que os manufaturados superam pouco mais de $50 \%$ do total das exportações. Nos países andinos, em cujas exportações pesam significativamente os bens energéticos e os minérios, o percentual de bens primários chega a atingir entre 80 e 90\% das exportações. Esses dados têm sido evocados para indicar os desafios que os países sul-americanos têm pela frente caso queiram viabilizar a integração regional, uma vez que ela passa necessariamente por equilibrar esses números.

Como visto acima, as condições necessárias para que o processo de integração avance praticamente inexistem no caso sul-americano. Por outro

\footnotetext{
3 Segundo Coutinho (2008, p. 66-71), a estabilidade política diz respeito à "ordem legitimamente aceita" uma vez que se caracteriza "pela aquiescência às instituições do regime político". Para o autor, uma crise institucional pode ser definida "como uma ameaça de ruptura ou colapso repentino das regras e organizações do regime político" e quando ocorrem instauram períodos de instabilidade política.
} 
lado, admite-se que alguns dos mecanismos que as precedem estejam em vigência. Segundo Nye, tais mecanismos são a articulação funcionalista de tarefas ou spillover, o acréscimo das transações, a existência de articulações e de coligações, a socialização das elites, a constituição de blocos regionais, a proximidade ideológica e identitária e o envolvimento de atores externos ao processo.

Em algumas ocasiões apostou-se na articulação funcionalista de tarefas ou spillover, responsável pela propagação da integração de um setor a outro. Na década de 1990, houve maior convicção do que atualmente de que o fomento de atividades em setores estratégicos, como o energético por exemplo, poderia suscitar interesse crescente em outros setores, e, por essa via, se estaria fomentando a integração à semelhança do que ocorreu na Europa por ocasião da exploração do aço e do carvão nos anos 1950. Contudo, fatores de ordem política interna aos países envolvidos interromperam ou, na melhor das hipóteses retardaram esse desfecho assim como minimizaram a potencialidade integradora de uma eventual proximidade ideológica e identitária. Outros mecanismos, como o acréscimo das transações, não produzem efeitos suficientes apesar de estarem em vigor. Sem dúvida, há nesta década fluxos de comércio e investimentos intrassul-americanos mais intensos do que em décadas precedentes. Contudo, para muitos analistas isso se deve meramente ao aumento global de tais fluxos e, em termos regionais, ainda não chegam a gerar uma sinergia integracionista. $\mathrm{O}$ envolvimento de atores externos ao processo tem sido mais motivo de preocupação quanto às possibilidades de aprofundamento do processo de integração do que o contrário, haja vista que as parcerias que tais atores extrarregionais ofertam onera os esforços intrarregionais de cooperação. ${ }^{4}$

Quanto às articulações deliberadas entre as partes, a formação de coligações, a socialização das elites e a constituição de blocos regionais, da mesma forma que os mecanismos anteriores estão em vigor, como bem atestam os esforços da chamada diplomacia presidencial. Contudo, também ainda não produzem os resultados necessários para tornar o processo autossustentável. Ou seja, tais mecanismos ainda não produziram as condições necessárias para o avanço da integração.

Particularmente relevante é o fato, lembrado acima, de que o processo de integração afeta a percepção dos agentes em pelo menos três dimensões

\footnotetext{
4 A presença da China e, mais recentemente, da Rússia e do Irã na região foi intensamente discutida no Grupo de Trabalho América do Sul e Regionalismos Comparados da Anpocs, em 2009. Além disso, a mais ostensiva presença dos Estados Unidos na Colômbia também é motivo de preocupação no que concerne a esse aspecto do debate.
} 
decisivas para sua continuidade. A primeira delas diz respeito à percepção quanto à distribuição dos benefícios, que deverão ser equitativos para que a percepção seja positiva. Quanto a isso, observa-se uma total insatisfação por parte dos países menores (Paraguai, Uruguai, Bolívia) que vêem o maior jogador (Brasil) como o principal beneficiário.

Outra dimensão diz respeito à percepção dos custos da integração, que deverão figurar como relativamente baixos para que a percepção seja positiva. Em situação de crise econômica e de instabilidade política qualquer custo se afigura como demasiadamente alto para os países mais pobres, de modo que os ganhos da integração teriam que ser ainda maiores para compensá-los. $\mathrm{O}$ mais comum é que, nesses casos, quaisquer vantagens de curto prazo sejam preferíveis a vantagens futuras relativamente maiores. Considerando que a adesão a estratégias de integração demanda algum cálculo quanto a custos imediatos e ganhos futuros, essa situação tende a retardar ou inviabilizar a adesão a elas, a menos que um ou mais dos envolvidos possa e queira arcar com os maiores custos imediatos, assegurando uma percepção positiva quanto à integração. Em relação a isso, como foi dito acima, o Brasil tem dado mostras de alguma superação do seu histórico isolacionismo e tem ido ao encontro de algumas demandas de seus vizinhos arcando com custos materiais e políticos da sua opção pela integração sul-americana. ${ }^{5}$

Finalmente, a percepção comum acerca de fatores externos - problemas econômicos, estratégicos, geopolíticos - também condiciona a adesão a estratégias de integração. Quanto a isso, há significativas diferenças na América do Sul. As próprias assimetrias regionais fazem com que os problemas econômicos incidam diferentemente nos países e gerem diferentes percepções quanto à magnitude das ameaças e a pertinência das soluções. Outros problemas de natureza política e estratégica, como os relacionados à defesa e à segurança regional, ao terrorismo, aos movimentos guerrilheiros e ao narcotráfico também são objeto de diferentes percepções, o que contribui, juntamente com as dimensões anteriores, para subtrair motivação à cooperação regional.

\section{Considerações finais}

Neste trabalho tecemos considerações acerca da integração sul-americana com base em algumas condições consideradas essenciais para o sucesso de um processo de integração por especialistas no assunto.

\footnotetext{
5 Há que considerar que os custos arcados pelo Brasil decorrem muito mais de esforços no sentido de projetar-se regionalmente do que de fomentar a integração uma vez que, agindo assim, consolida sua liderança regional sem sacrificar autonomia decisória.
} 
Embora essas categorias tenham sido recuperadas de literatura especializada sobre a integração européia, o que poderia ser de reduzida utilidade para estudar casos em contextos acentuadamente diferentes, entende-se que elas são suficientemente abstratas para assegurar sua aplicabilidade. Ademais, evitou-se traçar paralelos entre os dois processos de integração que pudesse ensejar a assimilação indevida de análises e conclusões.

Das categorias consideradas - compatibilidade de valores, previsibilidade mútua dos comportamentos, responsabilização mútua, simetria ou igualdade econômica das unidades, complementaridade positiva das elites, pluralismo, estabilidade interna - constatou-se que as assimetrias regionais e a instabilidade interna são as condições mais problemáticas no caso sul-americano, uma vez que impedem que haja avanços nas demais.

Um balanço do estudo realizado até aqui permite estimar que o processo de integração tende a ser mais longo e errático do que seria desejável, uma vez que se encontra no que poderia ser entendida como fase inicial de geração das condições básicas a partir da dinâmica instaurada por alguns mecanismos sustentados apesar das dificuldades e limitações.

\section{Referências}

BOUZAS, Roberto; VEIGA, Pedro da Motta; RÍOS, Sandra. América Latina: ¿integración o fragmentación? In: LAGOS, Ricardo (Org.). América Latina: ¿integración o fragmentación? Buenos Aires: Edhasa, 2008. p. 319-347.

CASTILLA, Luis Miguel. La agenda de competitividad en América Latina. In: LAGOS, Ricardo (Org.). América Latina: ¿integración o fragmentación? Buenos Aires: Edhasa, 2008. p. 349-384.

COUTINHO, Marcelo. Crise institucional e mudança politica na América do Sul. Rio de Janeiro: Edição do autor, 2008.

DEUTSCH, Karl. A integração política: condições fundamentais e processos. In: BRAILLARD, Philippe. Teorias das relações internacionais. Lisboa: Fundação Calouste Gulbenkian, 1990. p. 363-384.

DOUGHERTY, James; PFALTZGRAFF, Robert. Relações internacionais: as teorias em confronto. Lisboa: Gradiva, 2003.

HAAS, Ernest. International integrations: the European and the universal process. International Organization, Wisconsin, v. 15, n. 3, p. 366-392, 1961.

LIMA, Maria Regina Soares de. A politização da política externa e os interesses nacionais. Correio Brasiliense, Brasília, 11 jun. 2009. Disponível em: <http://. observatorio.iuperj.br>.

NYE, Joseph. Compreender os conflitos internacionais: uma introdução à teoria e à história. Lisboa: Gradiva, 2002.

. Peace in parts: integration and conflict in regional organization. Boston:

Little, Brown, 1971. 